\title{
LINEAR FRICTION WELDING OF METALLIC MATERIALS (Review)
}

\author{
I.V. ZYAKHOR, M.S. ZAVERTANNY and S.V. CHERNOBAJ \\ E.O. Paton Electric Welding Institute, NASU \\ 11 Bozhenko Str., 03680, Kiev, Ukraine. E-mail: office@paton.kiev.ua
}

\begin{abstract}
Capabilities and prospects for application of linear friction welding for joining various metallic materials, namely steels, titanium alloys, high-temperature nickel alloys and composite materials are considered. Parameters of the mode of linear friction welding for different material combinations and their mechanical properties are given. Structure of joints in linear friction welding is similar to that for other friction welding variants. Width of characteristic joint sections (zones of dynamic recrystallization, thermomechanical and thermal impact) depends on mode parameters - welding time, axial force, vibration amplitude and frequency. Modern tendencies in modelling of heat evolution and deformation in linear friction welding are analyzed. Cost reduction and improvement of reliability of equipment for realization of this process remain an urgent problem. At present the field of industrial application of this process is limited to aerospace companies, where components of gas turbine engines from titanium alloys are joined, and in the future application of high-temperature and nickel alloy and composite materials is possible. 35 Ref., 5 Figures.
\end{abstract}

$\boldsymbol{K} \boldsymbol{e} \boldsymbol{y} \boldsymbol{w} \boldsymbol{o} \boldsymbol{r} \boldsymbol{s}:$ linear friction welding, process stages, joint structure, modelling, titanium alloys, high-temperature nickel alloys, composite materials

Over an almost 60 year period of research and industrial application of friction welding $(\mathrm{FW})$ in the world, an extensive volume of information has been accumulated on joining various structural materials. About 20 variants of technological processes using frictional heating to produce permanent joints, surfacing, forming, welding up holes, producing riveted joints have been proposed and implemented in practice [1]. Rotational FW, which was invented back in 1956, became the most widely applied in different industries.

Method of vibrational FW was described practically in time with the start of FW commercial application. This method uses relative reciprocating displacement for surfacing and joining parts with rectangular cross-section [2, 3]. In 1969 the mechanism of reciprocating motion for low-carbon steel welding has been patented [4]

Method of vibrofrictional welding, which was later called linear friction welding (LFW), was widely applied for joining thermoplastic products [5], whereas its application for welding metallic materials was restrained by complexity and considerable cost of development of reliable equipment. At the end of 1980s, the requirements of leading enterprises in aerospace industry necessitated development of technologies and equipment for LFW of various alloys for creation of welded rotors of aircraft gas turbine engines (GTE).
In 1990 the Welding Institute put into operation the first specialized machine with electromechanical drive for LFW of metals. Successful welding of rectangular samples of $25 \times 6 \mathrm{~mm}$ section from carbon and stainless austenitic steels, aluminium alloy 5154, titanium alloy $\mathrm{Ti}-$ $6 \mathrm{Al}-4 \mathrm{~V}$ [6-8] was the starting point for such companies as Rolls Royce, MTU Aero Engines and Pratt \& Whitney showing active interest in LFW technologies. LinFic $^{\otimes}$ concept of LFW equipment based on application of high-precision computerized hydraulic force drives was developed and implemented through combined efforts of a group of eight European companies. Since that time leading research centers and enterprises of various countries started intensively working on development of equipment, studying LFW process, and its industrial application.

The objective of this review is analysis of technological capabilities and features of formation of metallic material joints in linear friction welding.

General characteristic of LFW process. LFW process schematic is shown in Figure 1, diagram of mode parameter variation in time in Figure 2.

Mechanism of welded joint formation at LFW is similar to that at rotational FW [9]. Welded joint forms in the following sequence:

- initial rubbing-in of friction surfaces. Relative displacement of surfaces results in breaking up of oxide and grease films on contacting microprotrusions with opening of juvenile sections, with formation and immediate breaking up of adhesion bridges;

- avalanche-like increase of the number of interacting microprotrusions, as well as actual contact area and fast increase of temperature in the butt; 


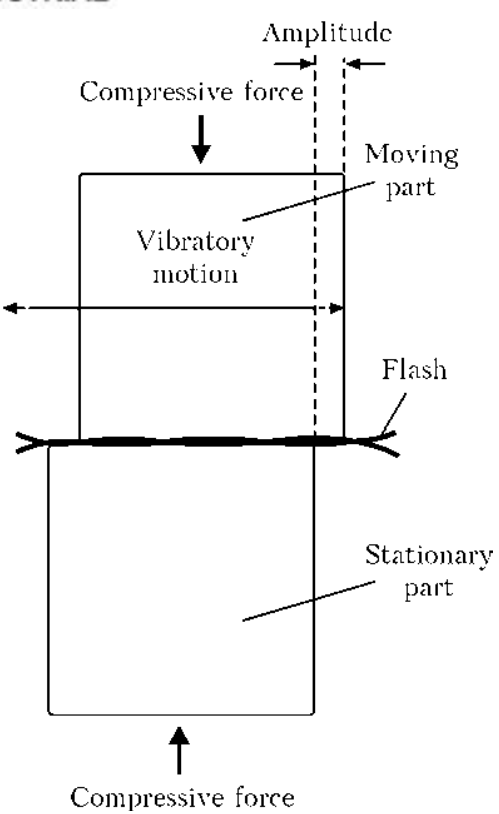

Figure 1. Schematic of LFW process

- upsetting start (driving plasticized metal out of the butt), increase of butt temperature up to a certain value;

- quasistationary (equilibrium) state of the friction process. Heat evolution power, temperature in the butt, and upsetting speed are at a certain set level;

- deceleration, i.e. controllable lowering of the speed of relative displacement to zero, during which the welded joint is formed;

- forging. Formed joint is subjected to compressive deformation by an axial force, which, as a rule, does not exceed the force applied at heating.

Unlike FW, at LFW the joint form is characterized by unusual flash (Figure 3). An essentially larger amount of flash forms on the faces in the direction of reciprocal displacement that is due to displacement of plasticized metal predominantly in the direction of vibrations.

LFW advantages. This method allows producing sound joints from various materials, such

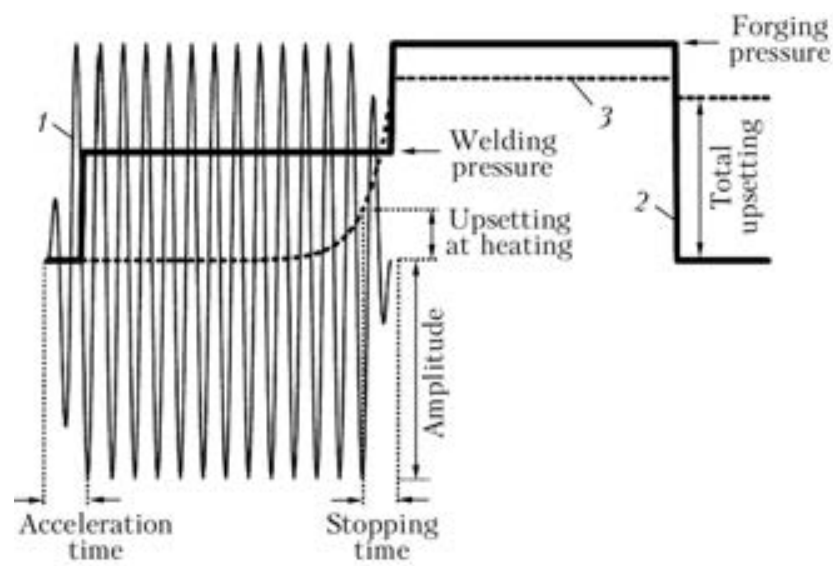

Figure 2. Diagram of variation of LFW parameters in time: 1 - amplitude; 2 - compressive force; 3 - upsetting

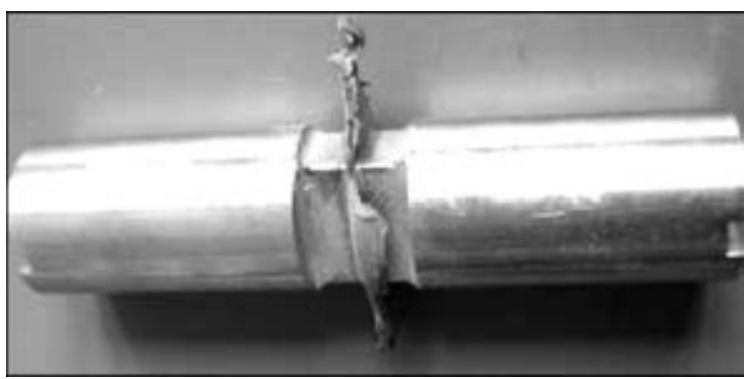

Figure 3. Welded joint of titanium alloy at LFW

as titanium and nickel alloys, different steels, aluminium and its alloys, composite materials (CM), etc. The main difference of LFW from rotational FW is the possibility of solid-phase welding of products with rectangular cross-section. LFW has several advantages, also inherent to other FW variants [6-9]:

- capability of joining parts from difficult-toweld materials both in similar and in dissimilar combinations;

- high efficiency;

- high and stable quality of the joints;

- hygienic value - absence of evolutions of harmful gases, ultraviolet and electromagnetic radiation;

- no need for application of filler materials, fluxes and shielding gases;

- joint forms in the solid phase, structural changes in the base metal proceed to a small depth;

- low energy consumption.

Main disadvantages of LFW are the high cost and complexity of equipment manufacturing, due to the need for application of high-rigidity highprecision force drives and sophisticated computerized control systems [7-9].

LFW parameters and materials being welded. The main parameters of LWF process are frequency and amplitude of reciprocal vibrations, pressure at heating and forging, heating and forging time, upsetting value at heating and total upsetting during welding (see Figure 2) [10]. Additional LFW parameters that can influence joint formation are time of acceleration and stopping of vibrations.

Works [11, 12] present results of LFW studies of $\mathrm{Ti}-6 \mathrm{Al}-4 \mathrm{~V}$ titanium alloy (Ti-64). Frequency of reciprocal vibrations in welding reached $119 \mathrm{~Hz}$ for vibration amplitude of 0.92 to $3 \mathrm{~mm}$. It is shown that to produce sound joints in LFW it is necessary to exceed a certain value of specific power of heat evolution that is determined as

$$
w=\frac{\alpha f P}{2 \pi A},
$$

where $\alpha, f$ is the amplitude and frequency of reciprocalting displacement, respectively; $P$ is the force; $A$ is the blank cross-sectional area. 
Producing sound joints (without pores or oxide inclusions) is possible in the case of simultaneous provision of certain critical conditions, namely, high enough values of vibration amplitude and frequency and welding pressure. By the data of [12] an important parameter for sound weld formation is total upsetting of blanks, its optimum value being different for different structural materials.

Work [13] gives the results of studies of LFW of aluminium, steel and high-temperature alloys, which were conducted on tee-joints of «pin-toplate» type with pin rectangular cross-section of $12 \times 4$ and $20 \times 4 \mathrm{~mm}$, respectively. It is shown that three properties of metallic material, namely high-temperature strength, heat conductivity and friction coefficient, dependent on temperature, are important for LFW. Materials quickly loosing their strength to great depth at heating, in particular, aluminium and aluminium alloy of AlMgSi1 system, are only partially suitable for LFW. Their stable heating requires ensuring considerable amplitudes and frequencies of reciprocating displacements at considerable welding force.

Study [14] gives a comparative characteristic of LFW and inertia FW. Investigations were conducted on samples from high-temperature aluminium alloy $\mathrm{Al}-11.7 \% \mathrm{Fe}-1.2 \% \mathrm{~V}-2.4 \% \mathrm{Si}$, produced by powder metallurgy techniques, as well as samples of this alloy with 2024-T351 aluminium alloy. It is shown that LFW allows reducing the intensity of thermodeformational welding cycle compared to inertia FW. Joint strength is about $81 \%$ of that of joints produced by intertia $\mathrm{FW}$ that is related to large coarsening of the grain and lower hardness in the joint zone. LFW mode for rods of $25 \mathrm{~mm}$ diameter is as follows: $50 \mathrm{~Hz}$ frequency, $2 \mathrm{~mm}$ amplitude, $4 \mathrm{~mm}$ upsetting, 30 and $50 \mathrm{kN}$ heating and forging forces, respectively.

In $[6,10,13,15]$ LFW capabilities at joining various steels (carbon, stainless, high-strength) were studied. Welding mode parameters were varied within the following ranges: $25-50 \mathrm{~Hz}$ vibration frequency, 1-3 $\mathrm{mm}$ amplitude, 40$240 \mathrm{MPa}$ heating force, and 1-3 $\mathrm{mm}$ upsetting. Authors of $[6,13]$ note that LFW of carbon steel runs into the following problems: welded joints have undercuts on both sides of the joint zone. This is attributable to low linear speed $(0.5 \mathrm{~m} / \mathrm{s})$, whereas it should be not less than $1 \mathrm{~m} / \mathrm{s}$ for steels to ensure uniform heating and stable deformation of metal.

Tensile testing of welded samples from carbon steel [15] showed ultimate strength of 539$592 \mathrm{MPa}$ with fracture through base metal (BM). Increase of metal microhardness in the joint zone by more than 2 times compared to BM is observed. At deviation of LFW parameters from optimum values towards their lowering, welded joints fail through the butt with low strength values.

Sound joints from stainless steel AISI 3L61 [16] were produced at more than $160 \mathrm{MPa}$ welding pressure and not less than $40 \mathrm{~Hz}$ vibration frequency. Mechanical testing showed ultimate strength of 549-610 MPa, relative elongation of 40-49\% with fracture running through BM. Failure of samples produced at less than $80 \mathrm{MPa}$ welding pressures or at $25 \mathrm{~Hz}$ vibration frequency ran through the weld. It is established that maximum upsetting speed, which influences the amount of $\delta$-ferrite in the joint zone, is achieved at high welding pressures and values of amplitude of $1.5 \mathrm{~mm}$ and frequency of $30 \mathrm{~Hz}$.

The greatest number of publications is devoted to studying LFW of various titanium alloys [6, 17-22] that is due to LFW practical application in manufacture of welded rotors of aircraft GTE compressors («blisks»). Publication authors studied the following ranges of LFW parameters variation: $0.5-3.0 \mathrm{~mm}$ amplitude, $15-150 \mathrm{~Hz}$ frequency, 50-190 $\mathrm{MPa}$ pressure at heating and $320 \mathrm{MPa}$ forging pressure.

In $[6,17]$ welded joints of $\mathrm{Ti}-6 \mathrm{Al}-4 \mathrm{~V}$ titanium alloy produced by LFW were studied. At rupture testing of welded samples of $25 \times 6 \mathrm{~mm}$ section [6] strength was $835 \mathrm{MPa}$ with fracture running through $\mathrm{BM}$. At bend testing fracture ran in the joint zone at bend angle of $50^{\circ}$. Mechanical testing of welded joints of $35 \times 26 \times$ $\times 13 \mathrm{~mm}$ model samples produced with upsetting limitation in welding of $1.75 \mathrm{~mm}$, showed the following results [17]: ultimate strength of 916 to $1004 \mathrm{MPa}$, relative elongation of $13.7-15.2 \%$, yield point of 841-968 MPa. Microhardness increase in the joint zone up to $H V 350$ (compared to $H V 300$ in $\mathrm{BM}$ ) was found at $\pm 0.6-1.0 \mathrm{~mm}$ distance from weld axis, depending on welding pressure.

Work [18] is a study of the possibility of LFW application for new titanium pseudo- $\beta$-alloy $\mathrm{Ti}^{-}$ $5553(\mathrm{Ti}-5 \mathrm{Al}-5 \mathrm{~V}-5 \mathrm{Mo}-3 \mathrm{Cr})$, as well as for IMI834 alloy $(\mathrm{Ti}-5.8 \mathrm{Al}-4 \mathrm{Sn}-3.5 \mathrm{Zr}-0.7 \mathrm{Nb}-0.5 \mathrm{Mo}-$ $0.3 \mathrm{Si}$ ). Mechanical testing of welded samples from Ti-5553 alloy showed that joint ultimate strength was equal to $94 \%$ of $\mathrm{BM}$ strength $(1042 \mathrm{MPa})$, yield point was $96 \%(1005 \mathrm{MPa})$, relative elongation was $36 \%$ of BM level. Lowering of microhardness in the joint zone by more than $17 \%$ compared to BM level at up to $\pm 1.6 \mathrm{~mm}$ distance from weld axis is found. Thermocouples were used to record the maximum temperature of friction surface at LFW of IMI-834 alloy in 
the temperature range of $750-800{ }^{\circ} \mathrm{C}$. It is shown that for IMI-834 alloy the nature of dependence of microhardness distribution on welding parameters, similar to that for Ti-64 alloy is preserved.

Work [19] is a study of LFW of titanium alloy Ti-6Al-2Sn-4Zr-6Mo (Ti-6246). Depending on heat treatment, this alloy can be regarded as $\beta$ alloy in one case, and as $\alpha+\beta$ alloy in another case. Investigations were performed on samples of $60 \times 36 \times 15 \mathrm{~mm}$ size. Welding of $\beta$-alloy and $\alpha+\beta$-alloy Ti-6246 was performed. Postweld heat treatment included heating up to $620{ }^{\circ} \mathrm{C}$ and soaking for $4 \mathrm{~h}$. At certain welding parameters welded joint ultimate strength $(1078 \mathrm{MPa})$ on the level of $96 \%$ of $\mathrm{BM}$ values of the less strong $\alpha+\beta$ Ti-6246 alloy, and yield point (1030 MPa) equal to $99 \%$ of this value for $\alpha+\beta$ Ti-6246 alloy, are reached.

In $[20,21]$ formation of dissimilar joints at LFW of titanium alloys VT6 and VT8-1 was studied. Welding was performed on $35 \times 26 \times 13 \mathrm{~mm}$ samples with specifying $2 \mathrm{~mm}$ upsetting. Mechanical properties of the joints were as follows: 990-1020 MPa ultimate strength, 924-939 MPa yield point, $11.39-13.78 \%$ relative elongation with fracture running through VT6 BM [21]. At testing of special samples with a recess along the joint line [20] for static tension, fracture ran through the thermomechanical impact zone (TMIZ) of VT8-1 alloy (ultimate strength of $1194 \mathrm{MPa})$. Here, the width of the joint TMIZ was not larger than $400 \mu \mathrm{m}$, its greater part being on VT8-1 alloy side.

Starting from the year 2000, the number of publications devoted to investigation of LFW of high-temperature nickel super alloys became much greater. Studied range of variation of super alloy LFW parameters was as follows: $2-3 \mathrm{~mm}$ amplitude, 40 to $100 \mathrm{~Hz}$ frequency, and 50$450 \mathrm{MPa}$ pressure.

In [22] the process of LFW of Waspalloy nickel alloy on $18 \times 13 \times 11 \mathrm{~mm}$ samples was studied. It is established that producing sound joints is possible at a certain, high enough value of all LFW technological parameters (amplitude, frequency, pressure). It is shown that at $0.9 \mathrm{~mm}$ distance from the friction surface (dynamic recrystallization zone - DRZ), metal temperature was not higher than $1126{ }^{\circ} \mathrm{C}$, that led to dissolution of strengthening $\gamma^{\prime}$-phase and microhardness lowering. At $3.3 \mathrm{~mm}$ distance on both sides of the weld microhardness lowering by $40 \%$ compared to BM values is observed. Producing sound joints (without pores or oxide inclusions) is achieved at more than $1.2 \mathrm{~mm}$ upsetting.
Work [23] is a microstructural study of joints of IN-738 nickel alloy. Samples of $12.8 \times 11.1 \times$ $\times 17.7 \mathrm{~mm}$ size were used for LFW. Complete dissolution of strengthening $\gamma^{\prime}$-phase to the depth of $600 \mu \mathrm{m}$ on both sides of the weld is observed in the joint zone. It is established that peak temperature during welding was higher than $1230{ }^{\circ} \mathrm{C}$.

In [24] optimization of LFW parameters for IN-718 nickel alloy was performed. Under certain conditions (for this alloy: $2 \mathrm{~mm}$ amplitude, $80 \mathrm{~Hz}$ frequency, $70 \mathrm{MPa}$ pressure), a temperature of about $1200{ }^{\circ} \mathrm{C}$ is reached on the friction surface. TMIZ is characterized by microhardness lowering by $25 \%$ compared to BM. Microscopic studies showed presence of dispersed oxides across the entire weld section, dimensions and amount of which depend on welding mode parameters.

Work [25] gives the results of studying LFW of CMSX-486 superalloy. Unlike titanium alloys, where flash has the form of «petals» common for both parts, for nickel alloys flash distribution into two individual «petals» is observed that is characteristic for joints at rotational FW. At tensile testing samples failed through BM. It should be also noted that conducted in [23, 25] microstructural analysis of welded samples of IN738 nickel superalloy and CMSX-486 single-crystal superalloy showed that melt areas can form in the alloys during LFW process. It is established that application of compressive load at the forging stage leads to rapid solidification of the formed metastable liquid phase.

Authors of [26] studied the applicability of LFW for EP742 nickel alloy on samples of $35 \times$ $\times 26 \times 13 \mathrm{~mm}$ size. Ultimate strength of welded joints was equal to $96-112 \%$ of the value required by TU specification, and relative elongation was 98-132\%. Width of DRZ and TMIZ was equal to 0.6 and $0.8 \mathrm{~mm}$, respectively. Microhardness drop in the joint zone is observed that is due to degradation of strengthening $\gamma^{\prime}$-phase.

LFW can be used to produce sound CM joints. In [27] joints of $\mathrm{CM}$ based on aluminium alloy AA2124 $(\mathrm{Cu}-3.8, \mathrm{Mn}-0.5, \mathrm{Mg}-1.4, \mathrm{Zn}<$ $<0.25$ ) reinforced by $25 \%$ of silicon carbide particles were studied. Sample size was $80 \times$ $\times 36 \times 15 \mathrm{~mm}$. Welding mode parameters were as follows: $50 \mathrm{~Hz}$ vibration frequency, $2 \mathrm{~mm}$ amplitude, $185 \mathrm{MPa}$ heating and forging force, and $2 \mathrm{~mm}$ upsetting. Mechanical testing of samples showed that ultimate strength of welded joint is equal to $82 \%$ of $\mathrm{BM}$ level, proof strength is $78 \%$ and relative elongation is $60 \%$ of $\mathrm{BM}$ value. Microhardness lowering in the welding zone by $10 \%$ compared to $\mathrm{BM}$ of $2124 \mathrm{Al} / 25 \mathrm{vol} \% \mathrm{SiC}$ composite is observed. 
Thus, as shown by analysis of publications, LFW application for nickel and titanium alloys is cost-effective, as here the cost of development of specialized equipment for aircraft engine construction products is justified. Weldability of titanium alloys was studied in similar and dissimilar combinations, whereas LFW capabilities for superalloy welding are limited to investigation of joints in similar combinations.

Welded joint structure. On the whole, metal structure at LFW is similar to that at rotational FW [9]. Typical welded joint structure at LFW is given in Figure 4 for the case of AISI 316L steel [16].

At LFW metal in the joint zone is heated up to temperatures not exceeding the melting temperature. However, owing to heat conductivity and external pressure blank metal changes its properties and structure to a certain depth from the friction surface. As a rule, four zones differing by texture and microstructure, are distinguished in the welded joint $[9,16,28]$ as follows:

1. DRZ, or fine-grain zone is the welded joint central part. Here, the metal undergoes phase transformations - an equiaxed fine-crystalline dynamically recrystallized structure forms;

2. TMIZ is characterized by metallographic texture. Grains and non-metallic inclusion stringers are elongated in the direction of deformation. In some materials phase transformations in this zone can also take place;

3. HAZ is the region between BM and TMIZ, where phase or structural transformations can proceed, unrelated to deformation process;

4. $\mathrm{BM}$ zone is the region where heating during welding did not have any noticeable influence on microstructure and mechanical properties.

Microstructural studies of samples of titanium alloys $\mathrm{Ti}-6 \mathrm{Al}-4 \mathrm{~V}$ in [18] and $\mathrm{Ti}-6 \mathrm{Al}-2 \mathrm{Sn}-4 \mathrm{Zr}-$ $6 \mathrm{Mo}$ in [19] welded by LFW showed that DRZ and TMIZ are directly proportional to welding time and inversely proportional to axial pressure, vibration frequency and amplitude. It is established that axial pressure is a determinant factor influencing DRZ and TMIZ dimensions.
For joints of similar materials structural changes are symmetrical relative to weld axis, unlike those for dissimilar material joints [20, 28].

LFW process modelling. In a number of studies an attempt has been made to apply calculation methods to describe energy characteristics of LFW process and determine the temperature mode of welding of various materials. In [29] it is proposed to determine the temperature in the butt at LFW at the moment before upsetting application from the following equation:

$$
\begin{gathered}
T=T_{0}+\frac{1}{c \rho F_{\tilde{n}} \sqrt{4 \pi a}} \int_{0}^{t} \frac{q(\tau)}{\sqrt{t_{\mathrm{h}}}-\tau} \times \\
\times \exp \left(-\frac{z^{2}}{4 a(t-\tau)}-b\left(t_{\mathrm{h}}-\tau\right)\right) d \tau,
\end{gathered}
$$

where $q(\tau)$ is the law of variation of evolved power in time; $t_{\mathrm{h}}$ is the heating time; $F_{\tilde{n}}$ is the rod cross-sectional area; $a$ is the thermal diffusivity factor; $b$ is the thermal efficiency factor; $c \rho$ is the volumetric heat capacity; $T_{0}$ is the initial temperature level.

Instant thermal power $q[7,10]$ evolved at friction can be determined from the following formula:

$$
q=F_{\text {fr }} v,
$$

where $F_{\mathrm{fr}}$ is the sliding friction force equal to

$$
F_{\text {fr }}=F k_{\text {fr }} ;
$$

where $F$ is the welding force; $k_{\mathrm{fr}}$ is the friction coefficient; $v$ is the sliding velocity (velocity of relative displacement of parts).

Sliding velocity [24, 27] depends on amplitude $\alpha$ and frequency $f$ of reciprocal motion. For amplitude variable by sinusoidal law, average sliding velocity $v_{\mathrm{sl}}$ is equal to

$$
v_{\mathrm{sl}}=4 \alpha f \text {. }
$$

For sinusoidal variation of amplitude, sliding velocity varies continuously from zero at peak amplitude up to maximum value at crossing a point, in which the blanks being welded are coaxial. Pressure in the contact zone also varies at peak amplitude it has the maximum value,

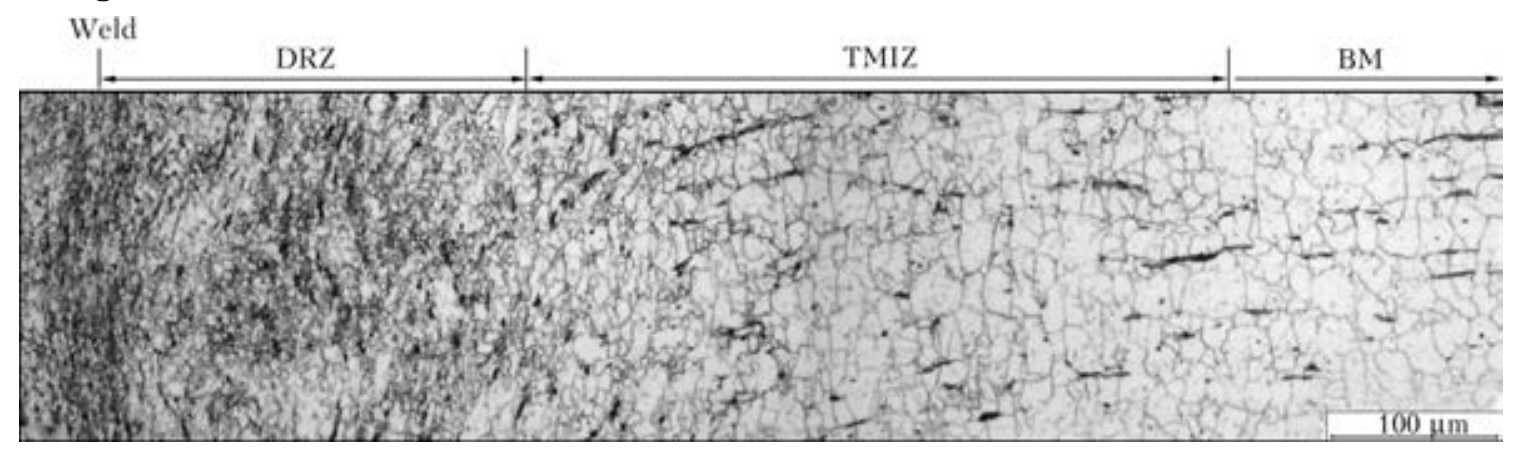

Figure 4. Microstructure of welded joint of AISI 316L steel 
and at zero crossing it has minimum value (corresponds to welding force).

To determine the total energy [10], required for welded joint formation, the expression for instant thermal power is integrated over welding process time $t$ :

$$
E_{x}=\int_{0}^{t} q d t=\int_{0}^{t} F_{\mathrm{fr}} v d t .
$$

Friction force depends on a whole number of factors $[1,2]$ : velocity of relative motion of friction surfaces; material nature and presence of surface films; temperature mode; normal pressure value; friction assembly rigidity and elasticity; stationary contact duration; load application speed nature of body contact; surface size; relative overlap coefficient; surface quality and roughness.

It is established [1] that at friction of steel sliding over steel, friction coefficient can vary in broad ranges (0.1-1.0, depending on welding conditions). Work [30] gives the data on friction coefficient variation during LFW for titanium alloys in the range from 0.25 up to 0.55 .

High intensity of physico-chemical processes proceeding in the joint zone at LFW makes mathematical modelling of this welding process a complex task, which is solved with application of computers and special software based on finite element method. Simplified models are used to reduce the time and computational power, for instance, calculation of temperature fields without allowing for material deformation, application of simplified 2Dmodels instead of 3D-modelling, consideration not

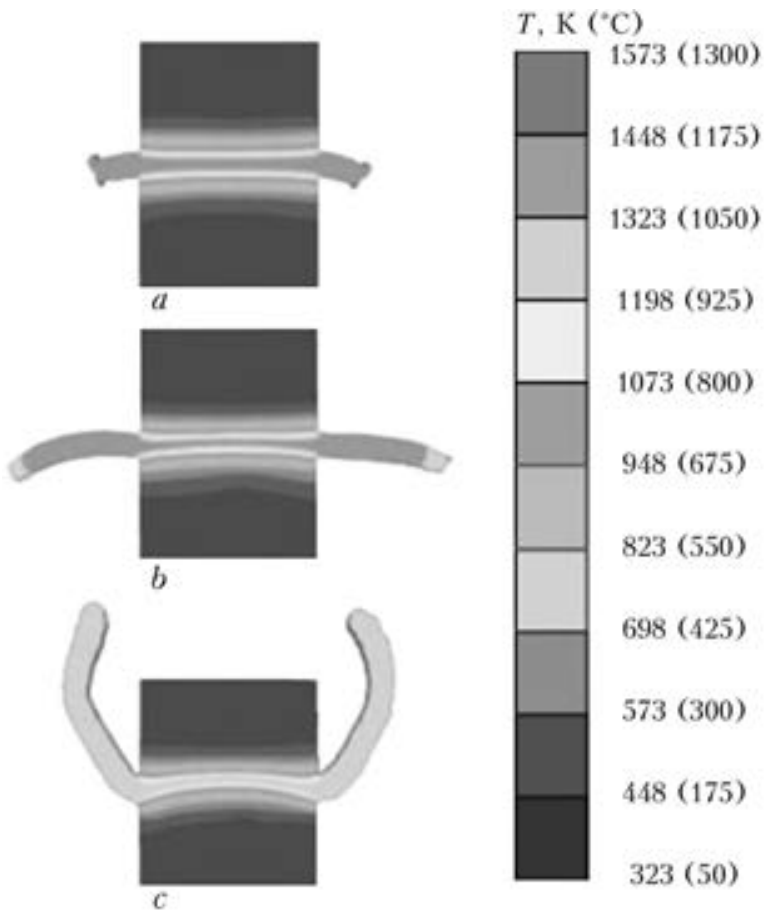

Figure 5. Results of 2D-modelling of Ti-64 alloy for low $(a)$, medium $(b)$ and high $(c)$ welding pressures [34] of the process as a whole, but of its individual stages; and prediction of the structure of individual welded joint zones [29-34].

Figure 5 gives the result of 2D-modelling of LFW process. Authors of [29-34] performed calculation of temperature fields at LFW of titanium alloys. It is established that for the studied parameters of welding VT6 alloy about $30 \%$ of thermal energy, generated in the butt during the process, is removed into the flash together with plasticized metal. Calculations show that during welding temperature on friction surface reaches $1300 \mathrm{~K}$, it, however, can go up even to $1500 \mathrm{~K}$, depending on LFW parameters. Here, temperature increase up to $1000{ }^{\circ} \mathrm{C}$ lasts for less than $1 \mathrm{~s}$ [31]. In [33] temperature fields were calculated for welded joint of VT6 + VT8M-1 alloys; temperature field asymmetricity relative to the joint line is noted.

In [31, 32] flash formation was modeled in addition to temperature fields. It is established that flash topology depends on welding mode parameters. Producing sound joints requires complete renewal of the friction surfaces and removal of contaminations into flash.

Upsetting speed depends on pressure, vibration amplitude and frequency. Their increase results in higher deformation and upsetting speeds, reduction of plasticized metal zone thickness and decrease of upsetting value required for surface cleaning. Increase of friction speed leads to higher maximum temperature in the butt, and with increase of welding pressure it decreases.

Authors of [31] suggested a model for prediction of HAZ structure in welded joint of Ti-64 alloy, as this zone is characterized by minimum strength and hardness. Size of $\beta$-phase grains is the main value of mechanical characteristics in this alloy HAZ. Therefore, this model is based on calculation of the size of $\beta$-phase grains after LFW, depending on welding mode and grain size before the process start.

In [30] modelling of LFW of links of roundlink chains from 30CrNiMo8 steel was performed. Temperature variation during welding was considered in two points removed for 3.5 and $4.5 \mathrm{~mm}$ from the butt. Data obtained by calculations differ only slightly from experimental data. Difference between calculated and experimental data on sample upsetting was equal of $13 \%$.

LFW process modelling is limited to mostly titanium alloys that is due to the urgency of this welding process application for manufacture of components of aircraft GTE. Joint formation at LFW of nickel superalloys, $\mathrm{Ni}-\mathrm{Al}, \mathrm{Ti}-\mathrm{Al}$ based intermetallics and CM in similar and dissimilar combinations is not well enough highlighted in 
publications that necessitates performance of further research.

\section{Conclusions}

1. Requirements of leading enterprises in aircraft propulsion engineering determined the urgency of development of technologies and equipment for LFW of parts from high-strength and hightemperature alloys. LFW allows producing sound joints of titanium alloys, different steels, high-temperature nickel alloys and CM.

2. Structure of joints in LFW is similar to that for other FW variants. Width of characteristic sections of the joint (zones of dynamic recrystallization, thermomechanical and thermal impact) depends on LFW mode parameters, namely axial force, welding time, vibration amplitude and frequency.

3. Mathematical modelling of LFW process, based on finite element method, allows assessment of thermodeformational conditions of joint formation and prediction of structural changes in materials in the welding zone.

4. Lowering of the cost and improvement of reliability of equipment for realization of LFW of high-temperature and high-strength materials remains to be a problem, limiting the field of LFW application to predominantly aerospace industry enterprises.

5. Performance of further studies on LFW of nickel superalloys, $\mathrm{Ni}-\mathrm{Al}, \mathrm{Ti}-\mathrm{Al}$ based intermetallics and $\mathrm{CM}$ in similar and dissimilar combination is urgent.

1. Lebedev, V.K., Chernenko, I.A., Vill, V.I. et al (1987) Friction welding: Refer. Book. Leningrad: Mashinostroenie.

2. Vill, V.I. (1962) Friction welding of metals. New York: American Welding Soc.

3. Vavilov, A.F., Voinov, V.P. (1964) Friction welding. Moscow: Mashinostroenie.

4. Maurya, R., Kauzlarich, J. Bonding apparatus friction welding by reciprocal motion. Pat. US 3420428-A. Publ. 1969.

5. Kulis, E.I., Lokishin, R.F. (1982) Friction welding of plastics. Svarochn. Proizvodstvo, 1, 8-9.

6. Nicholas, E.D. Hone, P. (1989) Developments in friction and MIAB welding. Welding Institute Bull. R382/11/89.

7. Nicholas, E.D. (1991) Linear friction welding. Duesseldorf: DVS Verl., DVS Berichte, 139, 18-24.

8. Nicholas, E.D. (1992) Friction surfacing and linear friction welding. In: Proc. of Int. SAMPE and Metals Proc. Conf. (Covina, CA, USA, 1992), 450-463.

9. Bhamji, I., Preuss, M., Threadgill, P.L. et al. (2010) Solid state joining of metals by linear friction welding: A literature review. Mater. Sci. \& Technol. $27(1), 2-12$

10. Usani, U. Ofem, Colegrove, P.A., Addison, A. et al. (2010) Energy and force analysis of linear friction welds in a medium carbon steel. Sci. and Technol. of Welding \& Joining, 15(6), 479-485.

11. Vairis, A., Frost, M. (1998) High frequency linear friction welding of a titanium alloy. Wear, 217, 117-131.

12. Wanjara, P., Jahazi, M. (2005) Linear friction weld ing of Ti-6Al-4V: Processing, microstructure and mechanical property interrelationships, metal. Mater. Transact. A, 36, 2149-2164.
13. Netwig, A. (1993) Entwicklung und Trends beim Reibschweissen. Der Praktiker, 9, 546-555.

14. Koo, H.H., Baeslack, W.A. (1992) Friction welding of rapidly solidified $\mathrm{Al}-\mathrm{Fe}-\mathrm{V}-\mathrm{Si}$ alloy. Welding $J$., 5, $20-24$

15. Addison, A., Threadgill, P. (2010) Initial studies of linear friction welding of $\dot{\mathrm{C}}-\mathrm{Mn}$ steel. Welding and Cutting, 4, 364-370.

16. Bhamji, I., Preuss, M., Threadgill, P.L. et al. (2010) Linear friction welding of AISI 316L stainless steel. Mater. Sci. and Eng., 528, 680-690.

17. Kallee, S.W., Nicholas, E.D., Russell, M.J. (2003) Friction welding of aeroengine components. In: Proc. of 10th World Conf. on Titanium (Hamburg, Germany, 2003), 2859-2867.

18. Evolution of microstructure, microtexture and mechanical properties in linear friction welded titanium alloys. digitool.library.mcgill.ca/thesisfile 103485. pdf

19. Corzo, M., Torres, Y., Anglada, M. et al. (2007) Fracture behaviour of linear friction welds in titanium alloys. Annales de la Mecanica de Fractura, $\mathbf{1}$, 75-80.

20. Diakonov, G.S., Izmajlova, N.F., Bychkov, V.M. et al. (2012) Examination of weld zone microstructure in linear friction welding of VT6 and VT8 titanium alloys. Vestnik UGATU, 16(7), 48-52.

21. Medvedev, A.Yu., Bychkov, V.M., Selivanov, A.S. et al. (2012) Application of linear friction welding for joining of VT6 and VT8-1 alloys. Ibid., 16(7), 63-67.

22. Chamanfar, A., Jahazi, M., Gholipour, J. et al. (2011) Mechanical property and microstructure of linear friction welded WASPALLOY. Metallurg. and Mater. Transact. A, 42(March), 729-744.

23. Ola, O.T., Ojo, O.A., Wanjara, P. et al. (2012) Analysis of microstructural changes induced by linear friction welding in a nickel-base superalloy. Ibid., 42 (Dec.), 3761-3777.

24. Linear friction welding of IN-718: Process optimization and microstructure evolution http://Www.scientific.net / AMR.15-17.357.

25. Ola, O.T., Ojo, O.A., Wanjara, P. et al. (2012) A study of linear friction weld microstructure in single crystal CMSX-486 superalloy. Metallurg. and Mater. Transact. A, 43(March), 921-933.

26. Bychkov, V.M., Selivanov, A.S., Medvedev, A.Yu. et al. (2012) Study of weldability of heat-resistant nickel alloy EP742 by method of linear friction welding. Vestik UGATU, 16(7), 112-116.

27. Rotundo, F., Ceschini, L., Morri, A. et al. (2010) Mechanical and microstructural characterization of $2124 \mathrm{Al} / 25 \mathrm{vol} \% \mathrm{SiCp}$ joints obtained by linear friction welding (LFWptA). Composites, 41, 1028-1037.

28. Karavaeva, M.V., Kiselyova, S.K., Bychkov, V.M. et al. (2012) Influence of upset value on formation of welded joint in linear friction welding. Pisma o $\mathrm{Ma}^{-}$ terialakh, 2, 40-44.

29. Medvedev, A.Yu., Pavlinich, S.P., Atroshchenko, V.V. et al. (2010) Modeling of temperature field in linear friction welding. Vestik UGATU, 14(2), 75-79.

30. Wen-Ya Li, Tiejun Ma, Jinglong Li. (2010) Numerical simulation of linear friction welding of titanium alloy: Effects of processing parameters. Materials and Design, 31, 1497-1507.

31. Grujicic, M., Arakere, G., Pandurangan, B. et al. (2012) Process modeling of $\mathrm{Ti}-6 \mathrm{Al}-4 \mathrm{~V}$ linear friction welding (LFW). J. Mater. Eng. and Performance, 21(10), 2011-2023.

32. The importance of materials data and modeling parameters in an FE simulation of linear friction welding. http: / / www.hindawi.com/ journals

33. Kiselyeva, S.K., Yamileva, A.M., Karavaeva, M.V. et al. (2012) Computer modeling of linear friction welding based on the joint microstructure. J. Eng. Sci. and Technol. Rev., 5, 44-47.

34. Turner, R., Gebelin, J.-C., Ward, R.M. et al. (2011) Linear friction welding of Ti-6Al-4V modeling and validation. Acta Materialia, 59, 3792-3803.

35. Linear friction welding of high strength chains. http: / www.raiser.de/download/innovationspreis bewerber2013/Linear_Friction_Welding of_High Strength_Chains_Mucic-Fuchs-Ē̄zinger.pdf

Received 09.10.2014 